\title{
Considerações sobre biografia científica e história transnacional das ciências: o caso da participação de Gleb Wataghin na cooperação ítalo-soviética (1959-1968)
}

\author{
Considerations on scientific biography and transnational \\ history of sciences: Gleb Wataghin participation's case in \\ the Italian-Soviet cooperation (1959-1968)
}

\author{
Luciana Vieira Souza da Silva ${ }^{1}$ \\ Doutora em Educação - História \\ da Educação e Historiografia \\ pela Faculdade de Educação \\ da Universidade de São Paulo. \\ Membro do grupo de pesquisa \\ História e Historiografia das \\ ideias e dos intelectuais da \\ educação. Mestra em Estudos \\ Culturais (EACH-USP) e \\ licenciada em Ciências da \\ Natureza (EACH-USP). \\ vssluciana@gmail.com
}

Recebido em: 31/01/2020

Aceito em: 15/04/2020

\section{Resumo}

Este artigo buscar explorar as possibilidades de interlocução entre a biografia científica e a história transnacional para a história das ciências, tendo como estudo de caso a participação do físico russo-italiano Gleb Wataghin na cooperação ítalo-soviética. A análise de trajetórias individuais tem se mostrado uma ferramenta a ser considerada na análise da construção de redes transnacionais. Entre os resultados, argumento sobre a possibilidade de que esses contatos tenham sido fruto de parte da expressão do habitus do físico, constituído em seu período brasileiro, quando trabalhou pela internacionalização da ciência, em acordo com as relações diplomáticas estabelecidas entre os países.

Palavras-chave: Gleb Wataghin. Biografia científica. História transnacional das ciências. Itália-URSS.

\section{Abstract}

The purpose of this article is to explore the interaction between the scientific biography and the transnational history in the history of sciences, by analyzing the case-study of the Russian-Italian physicist Gleb Wataghin's participation in the Italian-Soviet cooperation. Individuals trajectories analyzes have been considered tools to the analysis of the building of transnational networks. Among the results, I argue about the possibility that these contacts were the result of part of the expression of the physicist's habitus, constituted in his Brazilian period, when he worked for the internationalization of science, in accordance with the diplomatic relations established between the countries.

Keywords: Gleb Wataghin. Scientific biography. Transnational history of sciences. Italy-USSR. 


\section{Introdução}

O físico russo-italiano Gleb Wataghin trabalhou no Brasil entre 1934 e 1949. Primeiro professor contratado para o Departamento de Física da Faculdade de Filosofia, Ciências e Letras (FFCL) da Universidade de São Paulo (USP), Wataghin participou da organização das cadeiras de física; proferiu conferências públicas sobre temas como ciência, universidade e ensino secundário; atuou na formação de professores de física; e orientou a formação de físicos teóricos e experimentais (VIDEIRA; BUSTAMANTE, 1993; SILVA, 2016). A USP foi fundada em 25 de janeiro de 1934, após articulação política de membros do chamado grupo do Estado, como Júlio de Mesquita Filho, Armando de Salles Oliveira e Fernando de Azevedo ${ }^{1}$. A universidade foi formada a partir da reunião de faculdades já existentes, como a Escola Politécnica, a Faculdade de Medicina e a Faculdade de Direito. A novidade do empreendimento foi a criação da FFCL, unidade responsável por externalizar os dois principais objetivos da universidade: produzir cultura e ciência desinteressadas e formar professores para o ensino secundário. Com esses dois objetivos em mente (e no discurso público), os fundadores da USP buscavam dar origem a uma nova elite intelectual, que se ocuparia da direção do país (CARDOSO, 1982).

A tarefa delegada aos professores da FFCL foi de grande responsabilidade. Como consequência às críticas do grupo do Estado às elites intelectuais brasileiras do período, os dirigentes da universidade decidiram oferecer as cadeiras da FFCL a professores estrangeiros. Em uma divisão por nacionalidade, os professores franceses ficaram responsáveis pelas cadeiras de ciências humanas; os alemães pelas de ciências naturais; e os italianos pelas ciências exatas, literatura e língua italiana. Alguns anos depois, os italianos conseguiram a regência da cadeira de língua e literatura grega (WATAGHIN, 1992; PETITJEAN, 1996; SILVA, 2013; SILVA, 2015).

O físico Gleb Wataghin, embora nascido no Império Russo, emigrou com a família para a Itália em 1919, quando completou os estudos em física. Em 1929, conseguiu a nacionalidade italiana (PREDAZZI, 1999). Foi indicado a compor a missão italiana após a viagem à Europa do engenheiro, professor da Escola Politécnica e primeiro diretor da FFCL, Theodoro Ramos. Em princípio, Ramos pretendia contratar Enrico Fermi, que não aceitou o convite (WATAGHIN, 2010). Wataghin chegou ao Brasil pouco tempo após a fundação da USP. No período em que esteve no país, trabalhou pela internacionalização de seu Departamento, atraindo eminentes nomes da física e enviando seus estudantes para viagens de intercâmbio e pesquisa no exterior. Um caso notável foi a visita do estadunidense Arthur Compton, vencedor do prêmio Nobel de física de 1927, que veio ao Brasil em 1941 para realizar pesquisas, promover conferências e participar do Simpósio sobre Raios Cósmicos, no Rio de Janeiro. A visita de Compton foi incorporada às políticas diplomáticas estadunidenses para o Brasil, em tempos de Política de Boa Vizinhança, quando os EUA buscavam se aproximar dos países da América Latina visando, principalmente, ao apoio na Segunda Guerra Mundial. Neste tipo de relação, os interesses científicos eram tratados conjuntamente às políticas diplomáticas culturais (FREIRE Jr.; SILVA, 2014; 2019).

A visita de Compton não foi um caso isolado na trajetória de Wataghin no Brasil. Em minha tese de doutorado ${ }^{2}$, discuto as diferentes táticas do físico visando à ampliação de sua rede de sociabilidades, tendo em vista as modificações nos quadros de relações internacionais do Brasil. Em meus resultados, observei que além da Itália e dos Estados Unidos, Wataghin também estabeleceu colaboração estreita com a França. Extrapolando os limites do campo científico, se aproximou da comunidade russa de São Paulo, atuando como vice-diretor do Subcomitê Russo de Socorro às Vítimas de Guerra. Neste artigo, me proponho a discutir as ciências nas relações diplomáticas a partir de uma discussão sobre as possíveis interlocuções entre duas correntes metodológicas: a biografia científica e a história transnacional das ciências. Como estudo de caso, analiso a participação de Wataghin na cooperação cientifica ítalo-soviética, estabelecida a partir de 1959,

1 O nome grupo do Estado faz referência ao jornal O Estado de S. Paulo, ao qual os membros eram ligados, como diretores, redatores, entre outros. Para uma compreensão mais detalhada acerca das ações do grupo que levaram à fundação da USP, recomendo o estudo de Irene Cardoso (1982) e o de Fernando Limongi (1989).

2 "Ciência, universidade e diplomacia científica: a trajetória brasileira de Gleb Vassilievich Wataghin (1934-1971)", em fase de publicação. 
quando era diretor do Instituto de Física da Universidade de Turim. A hipótese trabalhada no artigo é a de que a participação de Wataghin nesta colaboração representa uma continuidade de suas ações iniciadas no período em que trabalhou no Brasil. Exploro a ideia de que a busca pela internacionalização, como uma ferramenta para a consolidação de suas redes de sociabilidade e de seu espaço de trabalho, pode ser tomada como a expressão de seu habitus, estruturado durante a sua experiência brasileira, entre 1934 e 1949. Na primeira parte do artigo, discuto as possibilidades analíticas para estudo de casos como o de Wataghin, de sujeitos que atuaram para além das fronteiras nacionais, tendo como base referencial teórico da análise biográfica e da história transnacional das ciências. Na segunda parte, analiso a participação de Wataghin na cooperação ítalo-soviética, entre 1959 e 1968. As fontes documentais foram consultadas no Arquivo Histórico da Universidade de Turim (Archivio Storico dell'Università di Torino) e no site da Hemeroteca Digital Brasileira ${ }^{3}$, onde foram consultados jornais do período.

\section{Biografia científica e história transnacional das ciências: possiveis interlocuções}

A análise da contratação de Gleb Wataghin para a cadeira de física da FFCL revela a participação das ciências nas relações diplomáticas entre Brasil e Itália. De um lado, a Itália fascista estava interessada em enviar intelectuais ao exterior, a fim de promover propaganda cultural. É notável que os documentos relacionados à contratação da missão italiana e à presença italiana na USP, de modo geral, estejam presentes nos arquivos do Ministério da Cultura Popular (Ministero della Cultura Popolare), no Arquivo Central do Estado, em Roma. Do outro lado dos bastidores da contratação da missão italiana, estava o Brasil, que contava com boas relações com a Itália. A cidade de São Paulo abrigava uma considerável comunidade de italianos e ítalo-brasileiros e, com a fundação da USP, abriu-se uma nova possibilidade de cultivar os laços diplomáticos estabelecidos entre os dois países (SILVA, 2015). No entanto, a análise individual da trajetória de Gleb Wataghin tem revelado especificidades de sua atuação intelectual no Brasil. Dentro de seu engajamento pela formação de físicos e pela construção de um espaço internacionalizado de ensino e pesquisa, Wataghin construiu uma rede de sociabilidades que variou de acordo com as mudanças no quadro político-diplomático brasileiro. Nos diferentes casos de cooperação científica dos quais Wataghin participou, é possível destacar a atuação individual como elemento constituinte de uma história transnacional; ainda que as fronteiras nacionais não possam ser ignoradas, a trajetória de um sujeito revela como as ciências, a cultura e mesmo as relações pessoais, por vezes, ultrapassam e ressignificam acordos estruturados de cima para baixo.

Embora as motivações para a circulação internacional dos cientistas (e do conhecimento que produzem) possam superar as fronteiras nacionais, o que permite que suas trajetórias sejam compreendidas como fenômenos transnacionais, inúmeras são as barreiras criadas pelos Estados-nação para controlar o acesso ao território. Dentre esses instrumentos, podem ser citados os vistos e os passaportes, criados para garantir a segurança nacional e impedir a entrada e a saída de pessoas e de conhecimentos indesejáveis (DANIELS, 2019). Portanto, ao analisar a trajetória específica de um cientista ou de um conjunto de conhecimentos que atravessa uma fronteira nacional, é importante considerar a interação entre os sujeitos e os instrumentos burocráticos criados pelos Estados.

Ao escrever sobre uma vida, uma premissa relevante colocada por Dosse (2015) é a de que a narrativa histórico biográfica não é unívoca. A história e a sociologia têm se ocupado de discutir as vantagens e as desvantagens desse tipo de abordagem para trabalhos científicos. O sociólogo Pierre Bourdieu (1986) critica a ideia de se escrever uma história de vida, por entender que tal ideia parte do pressuposto de que a vida é uma história e de que ela pode ser contada. Sua principal crítica deriva de uma visão de que os eventos de uma vida não podem ser narrados cronologicamente. Quando se trata de uma figura eminente de determinado campo, como um músico ou um artista, é comum que a biografia comece com a ideia de que aquela pessoa sempre teve inclinação para a atividade responsável por seu sucesso profissional, como se fosse um dom. Em

3 Disponível em: <http://bndigital.bn.gov.br/hemeroteca-digital/>. Acesso em 29 jan. 2020. 
se tratando de entrevistas, é comum que o entrevistado se perca em meio às memórias e crie conexões que imponham linearidade ao discurso. Para resolver o problema das narrativas biográficas, Bourdieu propõe uma dupla ruptura: o abandono da estrutura do romance linear e o questionamento da ideia de que a vida é dotada de sentido (BOURDIEU, 1986).

Para escapar do romantismo, que acompanha diversos trabalhos biográficos, Bourdieu (1986) sugere que a vida do sujeito seja analisada segundo o conceito de trajetória. Dentro dessa concepção, um mesmo sujeito, carregado por seu nome próprio, se deslocaria no espaço social e ocuparia diferentes posições. Em termos bourdiesianos, o agente social aplicaria as diferentes formas de capital acumulado em diferentes campos sociais. Os deslocamentos em uma trajetória não ocorrem de forma linear, podendo ocorrer de maneira justaposta, ou seja, é possível que um mesmo sujeito ocupe diferentes posições ao mesmo tempo. Em meio a tantas transformações e diferentes locais ocupados, o nome próprio, segundo Bourdieu (1986), é a única coisa que permanece ${ }^{4}$. Os diferentes espaços ocupados por um mesmo sujeito ao longo de sua vida resultam na formação de sua experiência. A formação da experiência de vida resulta no habitus, o qual, ao longo da trajetória, ao mesmo tempo em que é construído, é externalizado na forma de escolhas dentro de um espaço de possíveis. O habitus é uma leitura do mundo social e sua expressão resulta no estilo de vida do sujeito, por ser uma estrutura estruturada e estruturante ${ }^{5}$ (BOURDIEU, 1996; 2011).

As considerações de Bourdieu (1986; 1996; 2011) contribuem, sobretudo, como alerta para os cuidados com relação à biografia (ou à trajetória, para utilizar um de seus conceitos). Na historiografia, existem autores que consideram a biografia uma boa ferramenta analítica. Dentre as vantagens trazidas pela biografia científica, uma delas é a de que este tipo de análise pode auxiliar a compreender uma história cultural da ciência. Entender a vida de um sujeito de ciência é, também, compreender a prática científica de um determinado período, visto que a história de uma vida traz um pouco mais do que somente as ambições científicas do sujeito (TERRAL, 2006). O historiador que se vale da biografia deve ter consciência, porém, que seu trabalho jamais será concluído; não importa a quantidade de fontes que seja capaz de reunir, a narrativa sobre a vida de uma pessoa jamais será esgotada. O acesso (e a interdição ao acesso) a determinadas fontes também irá implicar em diferentes perguntas que podem ser colocadas, bem como em diferentes hipóteses que podem ser formuladas sobre sujeitos e objetos (DOSSE, 2015).

Escrever uma biografia científica é, também, escrever a ciência pela ótica de seus praticantes. A biografia pode ajudar a compreender de que modo a ciência integra-se à vida, à sociedade e à cultura. Ao estudar a vida de um cientista em seu tempo, abre-se a possibilidade de entender as diferentes formas de organização do universo científico, de acordo com o contexto em questão (TERRAL, 2006). A biografia do cientista, como qualquer biografia intelectual, impõe como desafio a problemática de que o sujeito a ser biografado se mostra ao mundo e se deixa ler por seus trabalhos - por sua vida pública - e não por seu cotidiano ${ }^{6}$. Mas a análise da obra, entendida como o produto final da ciência, não necessariamente permite que se compreenda as condições de sua produção. A análise biográfica, ao trazer à luz elementos do cotidiano, pode auxiliar a compreender as diferentes etapas de construção do conhecimento, incluindo a própria organização do trabalho, a mobilização das equipes e, no caso do presente artigo, as articulações políticas estabelecidas entre os sujeitos, os governos e as instituições. O significado de uma vida não é singular, mas plural, "não apenas pelo fato de as mudanças que a travessia do tempo implica, mas também pela importância a conceder à recepção do biografado e de sua obra que é correlativa do momento considerado e do meio que deles se apropria” (DOSSE, 2015, p. 375).

4 No artigo, Bourdieu (1986) não leva em consideração casos de pessoas que trocaram de nome ao longo da vida.

5 Segundo Bourdieu (2011, p. 164): "Estrutura estruturante que organiza as práticas e a percepção das práticas, o habitus é também estrutura estruturada: o princípio de divisão em classes lógicas que organiza a percepção do mundo social é, por sua vez, o produto da incorporação da divisão em classes sociais”.

6 O historiador francês Guy Thuillier se ocupou de algumas questões concernentes ao métier do historiador. Dentre os debates que propõe, toca na importância de se pensar o cotidiano como objeto, sem confundir com a história cultural, compreendendo o cotidiano como um objeto independente. Uma das implicações do cotidiano é a aplicação do tempo, que incide diretamente na distribuição das tarefas, tornando-o um dos múltiplos fatores que participam no trabalho intelectual (THUILLIER, 1998). 
O biógrafo também ocupa um lugar de relevo na biografia, pois, ainda que evite o anacronismo, as questões e hipóteses que coloca ao biografado são sempre contemporâneas, o que permite às novas gerações a produção de novas narrativas sobre os mesmos sujeitos. Um biografado não está imobilizado em seu período histórico, mas é construído a partir da diversidade de narrativas biográficas que podem ser elaboradas sobre a sua vida (DOSSE, 2015). Ao escrever a história de uma vida recente, um dos cuidados é entender que as práticas científicas, os objetos e os sujeitos devem ser entendidos em seus respectivos tempos (PORTER, 2006).

Outro aspecto interessante da biografia, quando empregada como ferramenta analítica para a história das ciências e dos cientistas, é a possibilidade de pensar o trabalho intelectual para além do mundo das ideias, abandonando noções como a de que existe um conhecimento por si só, em que as ideias podem ser desencorporadas daqueles que as pensam. Por isso, Shapin e Lawrence (1998) se propõem a pensar o cotidiano dos intelectuais e dos cientistas a partir de seus corpos, levando em consideração até mesmo seus hábitos relativos à prática de atividade física, alimentação, cuidados com a saúde, entre outros. Shapin (1989) também se atenta a outros sujeitos que protagonizam o cotidiano do trabalho científico, mas que são deliberadamente invisibilizados pela ciência e pela historiografia das ciências, como os técnicos. Dificilmente esses sujeitos são mencionados nas obras científicas, que costumam laurear e apontar como autores somente os chefes dos laboratórios e, às vezes, seus assistentes.

A análise do cotidiano de Wataghin no Departamento de Física, conforme empreendido em minha tese de doutorado, tem revelado que o físico orientou a construção de uma rede de sociabilidades visando à internacionalização de seu espaço de trabalho. Por isso, a história transnacional também tem se constituído uma ferramenta analítica interessante para entender a circulação dos cientistas. Nesse tipo de análise, determinados conceitos não são tomados como fixos, tais como as definições de ciência, Estado-nação, fronteiras nacionais e as relações que se constroem materialmente entre as escalas sociais macro e micro (PESTRE, 2012). As conexões firmadas pelos sujeitos e pelas instituições, cujo alcance ultrapassa as barreiras geográficas dos territórios nacionais, podem ser entendidas como narrativas transnacionais. O termo transnacionalismo é um adjetivo interessante para descrever "como indivíduos que vivem em um lugar diferente daqueles onde nasceram mantêm laços com seus países de origem ao mesmo tempo em que desenvolvem identidades e relações sociais no país em que se estabeleceram" (MINOR, 2019, p. 228, tradução minha).

No caso estudado por Minor (2019), a respeito da atuação do físico mexicano Manuel Sandoval Vallarta, que foi professor junto ao Massachusetts Institute of Technology (MIT), nos Estados Unidos, o conceito de migração não é suficiente para explicar a construção de relações transnacionais e por isso considera, também, as tomadas de ação individuais e a conjuntura histórica. A trajetória de Vallarta é ilustrativa de como os cientistas são capazes de construir uma rede de relações com outros sujeitos e instituições, tendo em vista os diferentes interesses envolvidos nos processos de negociação. Do ponto de vista historiográfico, análises fundadas em contextos nacionais específicos nem sempre contemplam trajetórias complexas de cientistas como Vallarta, que circularam por comunidades científicas de diferentes países. A análise histórica transnacional sugere que a análise não precisa, necessariamente, se circunscrever a uma conjuntura nacional única ou fixa. Para compreender a trajetória intelectual de sujeitos como Vallarta, Minor (2019) também leva em consideração a combinação de diferentes elementos de sua trajetória, como seus laços profissionais, pessoais e culturais.

Pensar as relações estabelecidas por sujeitos e instituições para além das fronteiras nacionais é uma abordagem complexa. A análise da trajetória dos cientistas, para além das ações tomadas localmente, permite situá-los como pontos em uma grande rede transnacional que mantém as pessoas conectadas, de acordo com diferentes motivações e aspirações. Mais do que um método analítico preestabelecido, o transnacionalismo pode ser adotado como uma perspectiva. Quando o conhecimento circula de um ponto a outro desta rede, perpassa diferentes instituições, relações sociais, interesses, práticas e políticas, passando por transformações. Além disso, o conhecimento cruza fronteiras em diferentes suportes, como livros, publicações, cartas e pessoas, tornando a própria circulação suscetível de investigação (KRIGE, 2019; BARANY; KRIGE, 2019).

A análise biográfica dos sujeitos de ciência, combinada com uma perspectiva historiográfica transnacional, pode auxiliar na compreensão de seus deslocamentos; de como constroem suas redes de sociabilidade; 
quais ferramentas utilizam para alcançar seus objetivos; como se relacionam com a política e com a burocracia de Estado. A seguir, será analisada a participação de Wataghin nos acordos ítalo-soviéticos, no período em que se encontrava à frente do Instituto de Física da Universidade de Turim, tendo em vista os aspectos de sua trajetória relacionados à internacionalização, especificamente, sua atuação diante de acordos diplomáticos que contemplavam as atividades do campo científico.

\section{Wataghin na colaboração ítalo-soviética}

A aproximação de Wataghin ao campo científico soviético pode ter relação com elementos estruturantes de seu habitus acumulados em sua experiência brasileira. Desde que chegou ao Brasil, o físico foi reconhecido como um cidadão italiano, não somente por ter a cidadania, mas também por ser membro de uma missão universitária a serviço do Ministério das Relações Exteriores da Itália ${ }^{7}$. Mesmo assim, Wataghin, desde o início, despertou a curiosidade da imprensa brasileira, que destacava que, a despeito de compor uma missão italiana, seu nome denunciava sua origem nacional. Segundo notícia publicada pelo jornal carioca Correio da Manhã, o físico era italiano, "não obstante o nome não o dizer". Wataghin nasceu em Birsula, na Ucrânia, Império Russo, estudou no ginásio imperial de Kiev e chegou estudar na Universidade de Kiev, entre 1918 e 1919. Sua família era de origem russa, nobre e abastada, e seu pai era engenheiro (PREDAZZI, 1999; MOSEYKINA, 2012). Wataghin e sua família deixaram a Rússia pós-revolucionária em 1919, emigrando para a Itália. Em depoimento, o físico declarou que, após deixar o país, foram

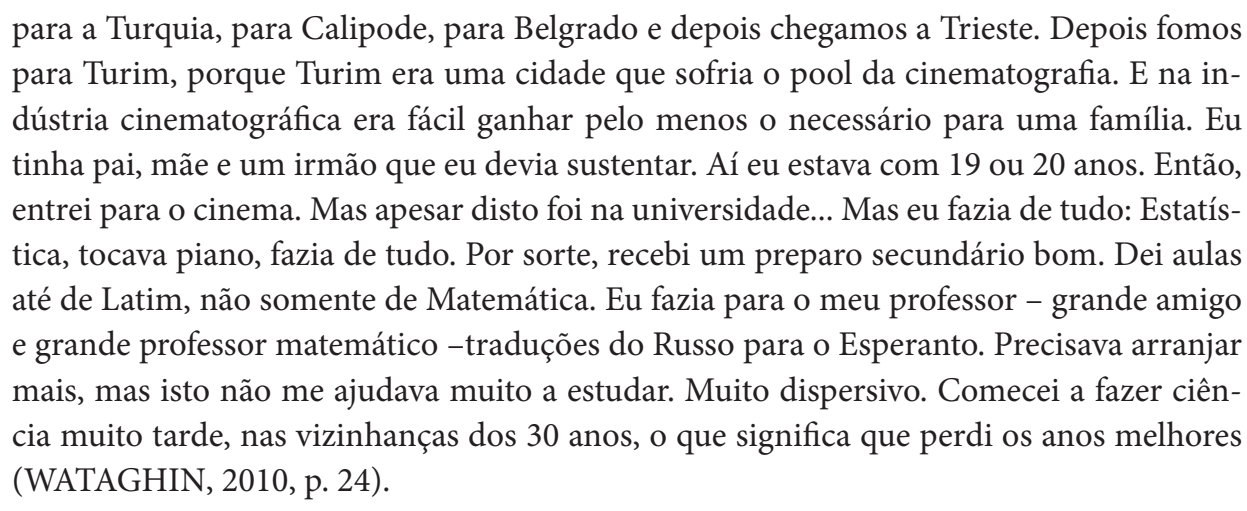

Não foram encontradas quaisquer referências - seja na literatura, seja nos documentos históricos - de que Wataghin tenha tentado se aproximar da União Soviética após sua chegada à Itália, em 1919. A primeira aproximação que se tem notícia, é sua participação na diretoria do Subcomitê Russo de Socorro às Vítimas de Guerra em São Paulo, nos anos de 1940․ Instituições culturais ligadas à comunidade russa foram autorizadas a funcionar em solo brasileiro somente quando o país reconheceu diplomaticamente a URSS, em 1945. Dois anos depois, as relações diplomáticas foram rompidas e essas instituições passaram a ser consideradas ilegais (MOTTA, 2007; ZEN, 2010). Segundo relato de Jacow Sacharowitsch Suriz, embaixador soviético no Brasil em 1945, entre milhares de pedidos de cidadania soviética, foi localizada uma carta de Wataghin que, no entanto, não teria obtido resposta (MOSEYKINA, 2013).

Conforme tenho observado em minhas análises a respeito de sua trajetória brasileira, em minha tese de doutorado, Wataghin regulou a construção de uma rede internacional de sociabilidades de acordo com as mudanças no quadro político diplomático, em uma época em que as relações científicas se encontravam

\footnotetext{
Archivio Storico dell'Università di Torino. Fascicolo personale Gleb Wataghin.

Correio da Manhã, Rio de Janeiro, 20 jun. 1934, p. 5.

A participação de Wataghin no Subcomitê Russo de Socorro às Vítimas de Guerra é discutida em minha tese de doutorado. As consequências políticas e científicas da participação de Wataghin nesse grupo foram tratadas em um artigo recentemente submetido à publicação, escrito em coautoria com meu orientador, professor Bruno Bontempi Jr. (FE-USP).
} 
embutidas nas políticas culturais. Sua participação no Subcomitê Russo de São Paulo e a tentativa de obter a cidadania soviética indicam que Wataghin pretendia se aproximar da URSS, o que foi possível somente alguns anos após seu retorno à Itália, conforme será discutido a seguir ${ }^{10}$.

Em fevereiro de 1960, foi assinado um acordo bilateral de política cultural entre Itália e URSS. O acordo ocorreu após discussões iniciadas em 1958 e consolidadas com a entrada de novos diplomatas no Ministério das Relações Exteriores italiano, após as eleições presidenciais. O acordo englobava arte, cultura, ciência, tecnologia e esporte, promovendo o intercâmbio de professores, estudantes, escritores, atores, jornalistas, entre outros (SALACONE, 2011). Os italianos passaram a interessar-se pela URSS após a ascensão de um governo de centro-esquerda na Itália. Uma das principais figuras desses acordos foi Amintore Fanfani, que ocupou o cargo de Presidente do Conselho de Ministros e de Ministro das Relações Exteriores da Itália nos anos 1960 (SALACONE, 2013).

A primeira visita de Wataghin à União Soviética, de acordo com os documentos consultados, ocorreu em julho de 1959, quando atendeu a um convite para participar, como delegado italiano, de duas conferências, uma em Moscou e outra em Kiev. Em Moscou, participou da "International Cosmic Ray Conference, held under the sponsorship of the International Union of Pure and Applied Physics (IUPAP)", a convite do físico italiano Bruno Rossi, que se encontrava no MIT, e de Dr. Zhdanov, secretário do comitê. Para a conferência de Kiev, "The 1959 Annual International Conference on High Energy Physics in Kiev, held under the sponsorship of the International Union of Pure and Applied Physics (IUPAP)", o convite oficial teria partido da Academia de Ciências da URSS. Para que Wataghin participasse do evento, o reitor da Universidade de Turim teve de pedir autorização ao Ministro da Instrução Pública italiano, uma vez que Wataghin também precisava de uma extensão da validade de seu passaporte ${ }^{11}$. O ano em que Wataghin solicita autorização para a viagem, 1959, coincide com o início do período de boas relações entre Itália e URSS, conforme analisado por Salacone (2011). O caminho percorrido entre o convite, o pedido de autorização para viajar, a carta do reitor ao ministro e a necessidade de estender a validade do passaporte de Wataghin, são demonstrativos de como não bastavam as boas relações entre os cientistas, era preciso enfrentar as barreiras colocadas pela burocracia de Estado.

Ainda em 1959, Wataghin convidou o professor Sokolov, da Faculdade de Física da Universidade Estadual de Moscou, para o encontro do Centro Studi Metodologici di Torino, que seria realizado em 8 e 9 de outubro. Além de diversos colegas italianos, deveriam participar P. Dirac e M. Fierz. Wataghin também convidou Sokolov a participar do Seminário de física teórica do Instituto, entre 7 e 10 de outubro, e do congresso da Sociedade Italiana de Física, de 1 a 6 de outubro, em Pávia ${ }^{12}$.

Nos anos de 1960, quando estavam vigentes as políticas diplomático-culturais firmadas entre Itália e URSS, Wataghin participou de diversos intercâmbios ${ }^{13}$. Conforme se observa, Wataghin costumava viajar para eventos na URSS, mas também apoiava pedidos de viagem de colegas italianos. Um dos casos localizados foi o de Guido Piragino, professor encarregado de exercícios de física da Universidade de Turim e colaborador do INFN, Istituto Nazionale di Fisica Nucleare, que pretendia realizar uma viagem de estudo e pesquisa à URSS, em 1962. Piragino ficaria de três a seis meses no Instituto Internacional de Pesquisas Nucleares de Dubna ou no Instituto de Física da Academia de Ciências da URSS, em Moscou, a fim de desenvolver pesquisas sobre física de partículas elementares ${ }^{14}$.

10 Além das ações de Wataghin dentro dos acordos culturais entre Itália e URSS, aqui analisadas, deve-se ressaltar que ele manteve intenso contato com cientistas soviéticos no período, como o físico Dmitri Ivanenko (1904-1994). Sobre esses contatos, ver os trabalhos de Moseykina (2012; 2013).

11 Archivio Storico dell'Università di Torino. Fascicolo personale Gleb Wataghin. Ofício do reitor da Universidade de Turim ao Ministério da Instrução Pública, Direção Geral de Instrução Universitária, Viaggio all’estero, 05/06/1959.

12 Archivio Storico dell'Università di Torino. Correspondência. Carta de Gleb Wataghin a Prof. A. A. Sokolov, 29/08/1959.

13 Archivio Storico dell'Università di Torino. Fascicolo personale Gleb Wataghin. Ofício do reitor da Universidade de Turim ao Ministério da Instrução Pública, Direção Geral de Instrução Universitária, Viaggio all’estero, 08/05/1965.

14 Archivio Storico dell'Università di Torino. Correspondência. Carta de Gleb Wataghin ao presidente do Conselho Nacional de Pesquisas da Itália, 01/02/1962. 
Em maio de 1962, Wataghin fez um pedido para participar de uma conferência internacional sobre energias elevadas que aconteceria em 1963, em Moscou. A fim de otimizar a viagem, informou que pretendia permanecer na União Soviética por mais dois meses, junto a alguma das seguintes instituições: Instituto de Física da Universidade Estadual de Moscou, Instituto de Física Teórica da Academia de Ciências da URSS de Moscou, Instituto Internacional de Energias Elevadas, em Dubna, ou no Instituto de Física de Lebediev, em Moscou. Em troca, durante a viagem, convidaria algum dos seguintes professores de física teórica da URSS para temporadas na Itália: N. N. Bogoliubov, D. D. Invanenko, A. A. Sokolov, ou outros ${ }^{15}$.

Em 1965, Wataghin pediu autorização para viajar novamente a Moscou, a fim de passar dois meses no Instituto de Matemática Steklov, à convite da Academia de Ciências da URSS, dentro da política cultural ítalo-soviética ${ }^{16}$. Um relatório detalhado dessa viagem foi apresentado por Wataghin ao Conselho Nacional de Pesquisas italiano. Wataghin saiu da Itália no dia 14 de maio e retornou em 9 de julho. A convite da Academia de Ciências da URSS, proferiu uma série de conferências sobre problemas teóricos que vinha estudando nos últimos dois anos, e que haviam sido publicados na revista italiana Il Nuovo Cimento e nos Rendiconti do Instituto Henri Poincaré, de Paris. Algumas conferências ocorreram no Instituto Matemático Steklov, no Instituto de Física de Dubna, no Instituto de Física da Academia de Ciências Lebedev, na Universidade de Leningrado e na seção siberiana da Academia de Ciências Novosibirsk (em Akademgorodok). Participou de colóquios e seminários do Instituto Matemático Steklov, de reuniões da seção de matemática da Academia, em dissertações de livre docência. Visitou laboratórios e importantes centros de pesquisa, em Dubna, Lebedev e Novosibirsk. As passagens de avião e as estadias foram pagas pela Academia de Ciências da URSS. Wataghin chegou a frequentar a casa de alguns dos matemáticos e físicos com os quais se encontrou e, enquanto estava no Centro Acadêmico de Novosibirsk, foi convidado por colegas da seção siberiana da Academia de Ciências a fazer uma viagem pelo lago de Baikal. Em Moscou, encontrou-se com o astrônomo armênio Prof. Ambarzumian, muito conhecido por seus trabalhos em astrofísica, com quem pôde discutir sobre o assunto. Wataghin apresentou trabalhos recentes da Escola de Física Teórica de Turim, particularmente de Tullio Regge, publicados em livro nos EUA, e falou da possibilidade de a obra ser traduzida e publicada na Rússia. Ressaltou que sua viagem foi de grande utilidade para a Escola de Física Teórica e Experimental de Turim ${ }^{17}$. O relato da viagem mostra que Wataghin estabeleceu contato com diferentes centros científicos soviéticos, cuja manutenção dos laços foi regulada também por possíveis relações de amizade, tendo em vista o contato mais próximo que estabeleceu com alguns dos cientistas. Em 1967, aceitou outro convite para ir à URSS, para ministrar um ciclo de conferências junto aos Institutos da Academia de Ciências da URSS, entre maio e junho ${ }^{18}$.

Parte da política cultural incluía o envio de periódicos. Wataghin enviou diversos exemplares da revista Il Nuovo Cimento para a Biblioteca da Academia de Ciências da URSS ${ }^{19}$. Nos arquivos da Universidade de Turim, constam diversas cartas relativas ao envio do periódico entre 1963 e $1968^{20}$. Como parte do intercâmbio, Wataghin também viabilizou que físicos soviéticos publicassem na revista italiana ${ }^{21}$.

Em 1966, na qualidade de diretor do Instituto de Física da Universidade de Turim, Wataghin receberia diversos físicos teóricos e experimentais soviéticos, indicados pela Academia de Ciências da URSS, entre os quais: D. I. Blochinzev, diretor dos Laboratórios Reunidos de Dubna; N. N. Bogoliubov, diretor do Instituto

15 Archivio Storico dell'Università di Torino. Correspondência. Carta de Gleb Wataghin ao presidente do Conselho Nacional de Pesquisas da Itália, 07/05/1962.

16 Archivio Storico dell'Università di Torino. Correspondência. Carta de Gleb Wataghin ao superintendente [questore] de Turim, 28/04/1965. Ver também: Carta de Gleb Wataghin ao Conselho Nacional de Pesquisas da Itália, 03/05/1965.

17 Archivio Storico dell'Università di Torino. Correspondência. Relatório de Gleb Wataghin sobre sua missão de estudos na URSS, apresentada ao Prof. Caglioti, presidente do Conselho Nacional de Pesquisas da Itália, 09/09/1965.

18 Archivio Storico dell'Università di Torino. Correspondência. Carta de Gleb Wataghin ao presidente do Conselho Nacional de Pesquisas, 13/01/1967.

19 Archivio Storico dell'Università di Torino. Correspondência. Carta de Gleb Wataghin ao reitor da Universidade de Turim, 15/02/1963.

20 Archivio Storico dell'Università di Torino. Correspondência. Carta de Gleb Wataghin ao reitor da Universidade de Turim, 04/05/1968.

21 Archivio Storico dell'Università di Torino. Correspondência. Carta de Gleb Wataghin ao Prof. Gilberto Bernardini, presidente da Sociedade Italiana de Física, 17/09/1965. 
Matemático "Steklov", da Academia de Ciências da URSS; D. D. Ivanenko, da Universidade Estadual de Moscou; A. A. Sokolov, da Universidade Estadual de Moscou; V. G. Kadishevsky, dos Laboratórios Reunidos de Dubna; Ludvig Faddeev, da Seção de Leningrado do Instituto Matemático "Steklov" (Academia da URSS); L. A. Khalfin, da Seção de Leningrado do Instituto Matemático "Steklov" (Academia da URSS); A. M. Budker, da Seção Siberiana da Academia da URSS; B. V. Medvedev, do Instituto Matemático "Steklov" da Academia de Ciências; V. A. Sidorov, da Seção Siberiana da Academia da URSS ${ }^{22}$. Conforme se observa, a posição de diretor foi fundamental para que Wataghin aplicasse o capital simbólico acumulado como gestor na aproximação com a ciência soviética, convertendo-o em capital científico e social.

Em 1968, Wataghin compôs uma comissão, com Edoardo Amaldi e Gianpietro Puppi, para tratar de um intercâmbio entre a Accademia Nazionale dei Lincei, de Roma, e o Joint Institute of Nuclear Researches, de Dubna. Este intercâmbio ilustra a divisão de obrigações entre cada país, perante os participantes. A academia italiana pagaria as despesas dos soviéticos na Itália, no valor de 300.000 liras por mês, além da viagem; o valor aumentaria de acordo com a qualificação do físico soviético designado à Itália. A academia pagaria, também, as despesas de viagem de físicos italianos, de Roma a Moscou, mas não pagaria viagens internas à União Soviética ${ }^{23}$.

Em setembro de 1968, o físico italiano Erasmo Recami recebeu um convite para permanecer até três meses no Instituto de Física da Academia de Ciências da URSS, uma viagem que fazia parte dos acordos de intercâmbio entre os institutos italianos e soviéticos. Wataghin encarregou-se de intermediar os trâmites da viagem de Recami, ao escrever uma declaração destinada a facilitar a obtenção de visto do colega junto às autoridades soviéticas. Segundo a declaração, Wataghin recebeu por telegrama o convite feito a Recami pelo Vice Diretor, professor Vitalii Schelest, além de uma confirmação verbal dos professores Shelest e Bogoliubov, com os quais esteve em $\mathrm{Kiev}^{24}$, demonstrando que as viagens à URSS não só lhe foram úteis para pesquisas, como também serviram à manutenção e à criação de laços, ampliando sua rede de sociabilidades. Um caso parecido foi o convite recebido por Guido Piragino, também em 1968, que usufruiu de um acordo entre a Accademia Nazionale dei Lincei, a Academia de Ciências da URSS e o Joint Institute of Nuclear Researches. O intercâmbio teria sido aprovado pela Accademia Nazionale dei Lincei e confirmado verbalmente por Bogoliubov a Wataghin, em viagem recente que fizera a Moscou ${ }^{25}$. Ainda que Itália e URSS contassem com relações diplomáticas, cada viagem dependia de um pedido de visto e, em cada pedido, era necessário justificar o motivo da viagem e ressaltar que os soviéticos estavam interessados na presença dos italianos em seu país, visto que eles eram apontados como os responsáveis pelos convites. Wataghin demonstrava ciência das regras do jogo, ao informar às autoridades universitárias e diplomáticas que além dos convites formais enviados por telegrama, ele havia conversado sobre os intercâmbios pessoalmente, em viagens anteriores à URSS, sinalizando que ele e sua rede italiana não eram estranhos aos soviéticos.

\section{Considerações Finais}

O conjunto de fontes mais expressivo utilizado neste artigo foi consultado no Arquivo Histórico da Universidade de Turim, principalmente cartas institucionais assinadas por Wataghin, na condição de diretor do Instituto de Física. Cabe, neste ponto, tecer algumas considerações sobre o papel das fontes documentais na escrita da narrativa histórica. Na introdução de How Knowledge Moves: Writing the Transnational History of Science and Technology, Krige (2019) ressalta a presença de discussões essencialmente nacionais na

22 Archivio Storico dell'Università di Torino. Correspondência. Carta de Gleb Wataghin ao presidente do Conselho Nacional de Pesquisas da Itália, 07/07/1966.

23 Archivio Storico dell'Università di Torino. Correspondência. Carta [do presidente da Accademia Nazionale dei Lincei] a N. N. Bogoliubov, diretor do Joint Institute for Nuclear Research, [1968].

24 Archivio Storico dell'Università di Torino. Correspondência. Declaração de Erasmo Recami, feita por Gleb Wataghin, 27/09/1968.

25 Archivio Storico dell'Università di Torino. Correspondência. Declaração de Guido Piragino, feita por Gleb Wataghin, 30/09/1968. 
historiografia das ciências, após o fim da Segunda Guerra Mundial. Parte disso se deveu à organização de arquivos e instituições científicas em níveis locais, regionais e nacionais. A história transnacional da ciência e da tecnologia, conforme proposto pelo volume organizado por Krige (2019), consiste mais em uma possibilidade analítica do que um método estrito. A partir de uma perspectiva transnacional, observa-se que os documentos institucionais podem contribuir para a elucidação de como as políticas diplomáticas funcionaram na prática. Mais do que isso, as cartas trocadas entre os cientistas, ainda que formais, podem trazer elementos que ilustram de que modo as boas relações diplomáticas foram mantidas e qual o papel dos cientistas, do conhecimento e dos produtos culturais nos acordos.

No caso aqui analisado, fica evidente o papel ativo exercido por Wataghin em suas diversas ações voltadas ao aproveitamento dos acordos culturais bilaterais entre Itália e URSS. Em muitos dos documentos analisados, encontram-se expressões que fazem referência explícita ao acordo cultural então vigente entre os países, o que justificaria pedidos de financiamento para a circulação de pessoas e de produtos culturais. Contribuíram para este cenário específico: cientistas, professores e conhecimento, materializado na forma de revistas e no convite a publicações. Enquanto os acordos diplomáticos viabilizavam a circulação internacional em suas diferentes formas (pessoas, conhecimentos e produtos), as instituições italianas e soviéticas também foram fundamentais para a manutenção dos laços, uma vez que eram as responsáveis por receber e enviar pessoal e material, bem como por financiar parte dos custos das viagens.

Não é possível ignorar as fronteiras nacionais, principalmente em casos como este, em que as políticas diplomáticas foram primordiais para a circulação internacional. No entanto, a análise da atuação de sujeitos específicos, conforme empreendido no estudo da participação de Wataghin no caso ítalo-soviético, coloca em evidência elementos que superam as fronteiras nacionais, como os interesses institucionais e de pesquisa. No caso específico de Wataghin, outro fator ainda deve ser considerado. Desde o período em que trabalhou no Brasil, o físico tentou se aproximar da URSS, ainda que por caminhos não estritamente relacionados ao campo científico. Tal aproximação não foi possível naquele momento, devido às frágeis relações brasileiras com a URSS. Com a nova política italiana dos anos de 1960 e os acordos culturais bilaterais estabelecidos com os soviéticos, tal aproximação finalmente tornou-se possível. O trabalho empreendido por Wataghin nesse estudo de caso pode ser compreendido como parte da expressão de seu habitus como professor, cientista e dirigente; assim como fizera no Brasil, Wataghin soube jogar com diferentes jogos de escala ${ }^{26}$ para promover a internacionalização de seu espaço de trabalho e, assim, expandir sua rede de sociabilidades.

\section{Agradecimentos}

À Fundação de Amparo à Pesquisa do Estado de São Paulo (processo FAPESP no 15/20490-8 e 17/237995), pelas bolsas concedidas. Ao meu orientador, professor Bruno Bontempi Jr. (FE-USP). À professora Anne Collinot (CNRS - Centre Alexandre Koyré), pelo seminário Lenquête biographique dans l’étude des sciences. Vie et travail scientifiques; as discussões sobre biografia científica apresentadas neste artigo são fruto dos debates ocorridos nos encontros do seminário, entre novembro de 2018 e fevereiro de 2019.

\section{Referências}

BARANY; Michael J.; KRIGE, John.. Afterword: Reflections on Writing the Transnational History of Science and Technology. In: KRIGE, John (Org.). How Knowledge Moves: Writing the Transnational History of Science and Technology. Chicago: The University of Chicago Press, 2019, p. 411-418.

BOURDIEU, Pierre. L'illusion biographique. Actes de la recherche en sciences sociales. V. 62-63, p. 69-72, jun. 1986.

Razões Práticas: Sobre a teoria da ação. Tradução. Campinas: Papirus, 1996.

. A Distinção: crítica social do julgamento. Tradução. 2a ed., Porto Alegre: Zouk, 2011.

26 Sobre a micro-história e os diferentes jogos de escala na narrativa histórica, ver Revel (1998). 
CARDOSO, Irene. A Universidade da Comunhão Paulista: O projeto de criação da Universidade de São Paulo. São Paulo: Editora Autores Associados/ Cortez Editora, 1982.

DANIELS, Mario. Restricting the Transnational Movement of "Knowledgeable Bodies". The Interplay of US Visa Restrictions and Export Controls in the Cold War. In: KRIGE, John (Org.). How Knowledge Moves: Writing the Transnational History of Science and Technology. Chicago: The University of Chicago Press, 2019, p. 35-61.

DOSSE, François. O Desafio Biográfico. Escrever uma vida. São Paulo: EDUSP, 2015.

FREIRE Jr., Olival; SILVA, Indianara. Diplomacia e ciência no contexto da Segunda Guerra Mundial: a viagem de Arthur Compton ao Brasil em 1941. Revista Brasileira de História. São Paulo, v. 34, n. 67, p. 181-201, 2014.

. Scientific Exchanges between the United States and Brazil in the Twentieth Cetury: Cultural Diplomacy ans Transnational Movements. In: KRIGE, John (Org.). How Knowledge Moves: Writing the Transnational History of Science and Technology. Chicago: The University of Chicago Press, 2019, p. 281-307.

KRIGE, John. Introduction: Writing the Transnational History of Science and Technology. In: (Org.). How Knowledge Moves: Writing the Transnational History of Science and Technology. Chicago: The University of Chicago Press, 2019, p. 1-31.

LIMONGI, Fernando. Mentores e clientelas da Universidade de São Paulo. In: MICELI, S. (Org.). História das Ciências Sociais no Brasil. Vol. 1, São Paulo: Vértice, Ed. Rev. dos Tribunais: IDESP, 1989, p.111-187.

MINOR, Adriana. Manuel Sandoval Vallarta: The Rise and Fall of a Transnational Actor at the Crossroad of World War II Science Mobilization. In: KRIGE, John (Org.). How Knowledge Moves: Writing the Transnational History of Science and Technology. Chicago: The University of Chicago Press, 2019, p. 227-253.

MOSEYKINA, Marina. Ученый-физик Глеб Васильевич Ватагин: русский эмигрант, гражданин Италии. Русские в Италии. Итальянцы в России. Взаимовлияние культур. Мат-лы Междунар. заочн. науч. конф. (Санкт-Пе-тербург, май 2011 г.) / Отв. ред. и сост. Ю.Н. Жуков. - СПб.: Изд-во СпбГАСУ, р. 79-90, 2012.

. Отец Бразильской ядерной физики. Глеб Васильевич Ватагин в Сан-Пауло. РОДИНА. Moscou, n. 10, p. 62-64, 2013.

MOTTA, Rodrigo Patto Sá. O Perigo é Vermelho e vem de Fora: O Brasil e a URSS. Locus: Revista de História. Juiz de Fora, v. 13, n. 2, p. 227-246, 2007.

PESTRE, Dominique. Concluding remarks. Debates in transnational and science studies: a defence and illustration of the virtues of intellectual tolerance. British Society for the History of Science. V. 45, n. 3, p. 425-442, 2012.

PETITJEAN, Patrick. As missões universitárias francesas na criação da USP. In: HAMBURGER, Amélia Império et al. (Org.). A ciência nas relações Brasil-França (1850-1950). São Paulo: EDUSP, 1996, p. 259-330.

PORTER, Theodore M. Is the life of a scientist a scientific unit? Isis. V. 97, n. 2, p. 314-321, 2006.

PREDAZZI, Enrico. Gleb Wataghin. In: ROERO, Clara Silvia (Org.). La Facoltà di Scienze Matematiche Fisiche Naturali di Torino. 1848-1998. Tomo Secondo. I Docenti. Torino: Deputazione Subalpina di Storia della Patria/Università degli Studi di Torino, 1999, p. 283-294.

REVEL, Jacques. Microanálise e construção do social. In: REVEL, Jacques (Org.). Jogos de escalas: a experiência da microanálise. Tradução. Rio de Janeiro: Editora Fundação Getúlio Vargas, 1998, p. 15-38.

SALACONE, Alessandro. A cinquant'anni dall'accordo culturale tra Italia e URSS. In: BENIGNI, Valentina; SALACONE, Alessandro (Org.). Ulica Ševčenko 25, korpus 2. Scritti in onore di Claudia Lasorsa. Roma: Caissa, 2011, p. 1-11.

. Le relazioni italo-sovietiche negli anni dell'avvio del centro-sinistra e dei primi tre governi Moro nelle carte della diplomazia sovietica. In: MORO, Renato; MEZZANA, Daniele (Org.). Le relazioni italo-sovietiche negli anni dellavvio del centro-sinistra e dei primi tre governi Moro nelle carte della diplomazia sovietica. Soveria Mannelli: Rubbettino, 2013, p. 443-465.

SHAPIN, Steven. The Invisible Technician. American Scientist. V. 77, n. 6, p. 554-563, 1989.

SHAPIN, Steven.; LAWRENCE, Christopher. Introduction: The body of knowledge. In: LAWRENCE, Christopher; SHAPIN, Steven (Org.). Science Incarnate. Historical Embodiments of Natural Knowledge. Chicago/Londres: The University of Chicado Press, 1998, p. 1-19.

SILVA, André Felipe Cândido da. A diplomacia das cátedras: a política cultural externa alemã e o ensino superior paulista - os casos da USP e da Escola Paulista de Medicina (1934-1942). História. São Paulo, v. 32, n. 1, p. 401-431, jan./jun. 2013. 
SILVA, Luciana Vieira Souza da. A Missão Italiana da Faculdade de Filosofia, Ciências e Letras da Universidade de São Paulo: ciência, educação e fascismo (1934-1942). Dissertação (Mestrado em Estudos Culturais). Escola de Artes, Ciências e Humanidades, Universidade de São Paulo, 2015.

A circulação das ideias de Gleb Wataghin sobre ensino superior e secundário: as conferências públicas promovidas pela FFCL-USP a partir de 1934. In: 15 Seminário Nacional de História da Ciência e da Tecnologia, $15^{\circ}$ SNHCT, 2016, Florianópolis - SC. Anais... VÁSQUEZ, Maria Fernanda; CAPONI, Sandra; SILVA, Márcia Regina Barros da (Org.). Rio de Janeiro: Sociedade Brasileira de História da Ciência: Universidade Federal de Santa Catarina, 2016, p. 1-13.

TERRAL, Mary. Biography as cultural history of science. Isis. V. 97, n. 2, p. 306-313, jun. 2006.

THUILLIER, Guy. L’histoire entre le rêve et la raison. Introduction au métier de l'historien. Paris: Economica, 1998.

VIDEIRA, Antonio Augusto Passos; BUSTAMANTE, Martha Cecilia. Gleb Wataghin en la Universidad de São Paulo: un momento culminante de la ciencia brasileña. Quipu. V. 10, n. 3, p. 263-284, 1993.

WATAGHIN, Gleb. Gleb Wataghin (depoimento, 1975). Rio de Janeiro, CPDOC, 2010. 45 p.

WATAGHIN, Lucia. Fundação da Faculdade de Filosofia, Ciências e Letras da Universidade de São Paulo: a contribuição dos professores italianos. Rev. Inst. Est. Bras. São Paulo, n. 34, p.151-174, 1992.

ZEN, Erick Reis Godliauskas. Imigração e Revolução: Lituanos, Poloneses e Russos sob Vigilância do Deops. São Paulo: Editora da Universidade de São Paulo, FAPESP, 2010. 